\title{
Age and Disease Related Telomere Manifestations - A Review
}

\author{
Nurul Fatihah Mohamad Nasir ${ }^{1}$, Thirumulu Ponnuraj Kannan ${ }^{1,2, *}$, Siti Amrah \\ Sulaiman $^{3}$, Shaharum Shamsuddin $^{4}$, Azlina Ahmad ${ }^{1} \&$ Stefan Stangaciu ${ }^{5}$ \\ ${ }^{l}$ School of Dental Sciences, Universiti Sains Malaysia 16150 Kubang Kerian, Kelantan, Malaysia \\ ${ }^{2}$ Human Genome Centre, School of Medical Sciences, Universiti Sains Malaysia 16150 Kubang Kerian, \\ Kelantan, Malaysia \\ ${ }^{3}$ Department of Pharmacology, School of Medical Sciences, Universiti Sains Malaysia, 16150 Kubang Kerian, \\ Malaysia \\ ${ }^{4}$ School of Health Sciences, Universiti Sains Malaysia, 16150 Kubang Kerian, Malaysia \\ ${ }^{5}$ Apitherapy Consulting \& Trading International SRL, Sat Mereni, str. Principala nr. 106A, Comuna Contesti, \\ Dambovita district, Postal code 137133, Romania
}

\begin{abstract}
Telomeres are long repetitive DNA sequences of TTAGGG located at the end of the linear chromosomes and bound by shelterin proteins. Shelterin proteins function as the protection for the loop structure of telomere, which prevents the chromosome ends uncapped; resemble a DNA break and activates DNA repair mechanism. Telomeres are maintained by an enzyme called telomerase. Telomerase is not expressed in normal human somatic cells. Therefore, telomeres shorten with every cell division and limit the number of cell division. This limitation of cell division is termed replicative aging, which is thought to be a barrier to cancer formation. In addition, telomere shortening can induce replicative senescence which then leads to aging and human aging-associated diseases such as cancer and atherosclerosis. Several studies on human premature aging diseases such as congenital dyskeratosis and aplastic anemia also reported association between them and telomere length.
\end{abstract}

Keywords: aging, cancer, senescence, telomerase, telomeres

\section{INTRODUCTION}

Often, we exclaim on seeing a person, "Wow... You don't look like you are forty" or "You look too young for your age". Aging represents numbers inescapably in an ascending order, from which the human race wants to free itself to continue to be young. It seems that the current research in molecular biology does not appear to agree with the saying of Mark Twain "Age is an issue of mind over matter. If you don't mind, it doesn't matter". The two inevitable companions of aging, which are diseases and death, have long fascinated mankind and spurred the search for eternal youth. Advances in medical science, improved hygiene and nutrition and significant declines in mortality rates among the young have seen the increase in life expectancy and health span of humans [1]. According to Gompertz [2] aging is defined as a process that is associated with the steady decline in the performance of organ systems resulting in the loss of reserve capacity which in turn leads to an increased chance of death. In some organ systems, this loss of reserve capacity with increasing age can be attributed to the loss of cell function [3]. Telomere maintenance has been shown to be linked to aging [4]. The study conducted by Hayflick in 1961 has shown that the cultured human fibroblasts have limited number of cell divisions. This limitation which is currently referred to as Hayflick factor suggests the existence of internal counting mechanism within the cell [5]. The subsequent study then showed that the telomeres shorten with every cell division. These observations have suggested that the telomere loss is the molecular clock that drives aging [6-9]. Telomere shortening triggers a state of irreversible growth arrest termed replicative senescence [10]. This happens because dysfunctional telomeres are recognized as DNA damage and activate the DNA damage response pathway. This results in the activation of p53 [11,12] which will then lead to the growth arrest of cells, apoptosis and senescence in stem and progenitor cells [13-16]. This review explores on the association of telomeres are associated with aging and diseases. 

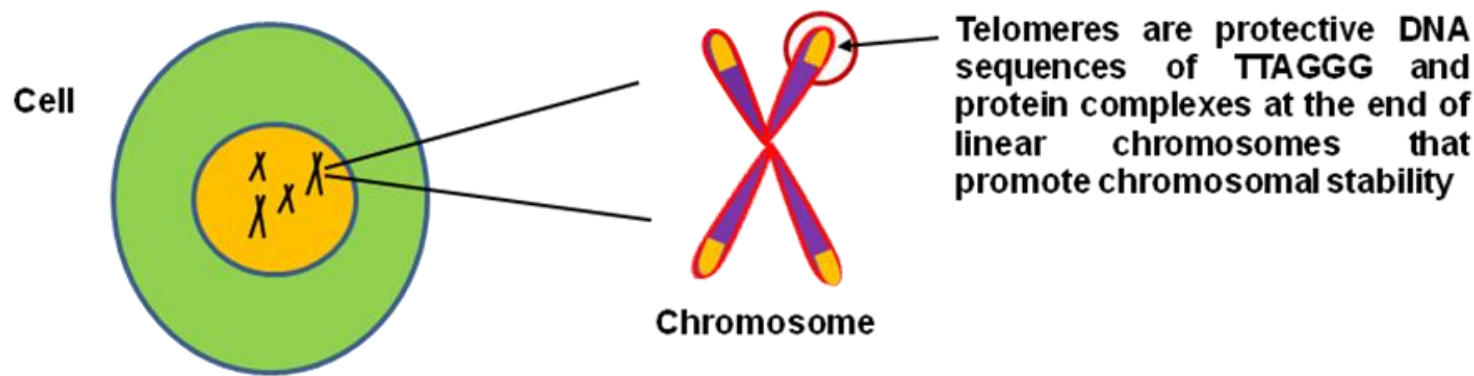

Telomeres shorten with every cell division
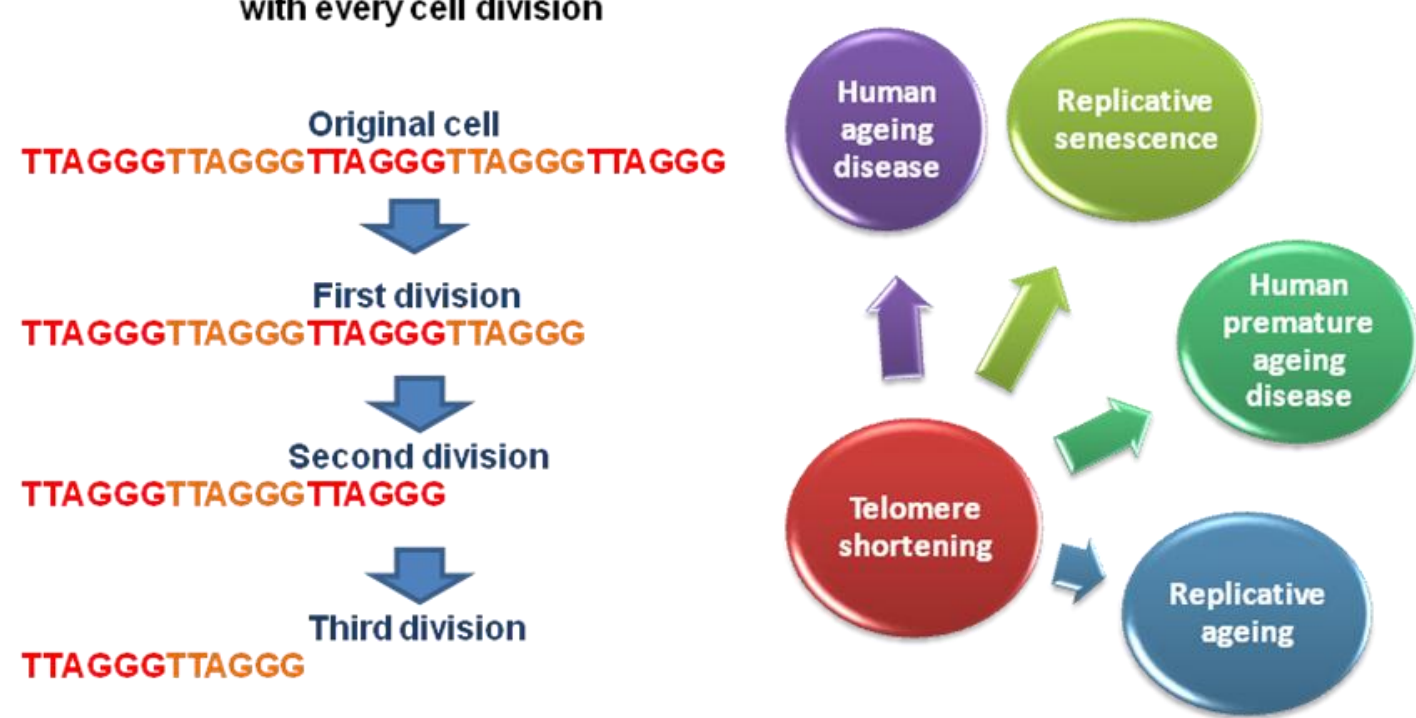

Figure 1: Telomeres are protective DNA sequences of TTAGGG which are located at the end of the linear chromosomes, supporting the chromosomal stability. With every cell division, telomeres shorten. As a result, it leads to replicative ageing, replicative senescence, human premature ageing disease and human ageing disease.

\section{WHAT ARE TELOMERES?}

Telomeres are the long repetitive DNA sequence of TTAGGG located at the end of the linear chromosomes $[17,18]$ and bound by shelterin proteins. The best known shelterin proteins in human cells are telomere repeat binding factors 1 (TRF1) and telomere repeat binding factor 2 (TRF2). TRF1 and TRF2 are both the negative regulators of the telomeric length [19]. Other shelterin proteins include protection of telomeres 1 (POT1), tripeptidyl peptidase 1 (TPP1), tripeptidyl peptidase 2 (TIN2) and repressor activator protein 1 (RAP1). Shelterin proteins function as the protection for the loop structure of telomere, which prevents the chromosome ends uncapped; resemble a DNA break and activates DNA repair mechanism [20]. The telomeric repeat does not encode for protein [21]. However, it consists of G-rich hexanucleotides repeats which enable the singlestranded telomere $\mathrm{G}$ overhangs form G-quadraplexes. The G-quadraplexes structure of telomeres is believed to be involved in telomere protection, suppression of recombination and inhibition of telomerase-dependent telomere extension [22]. It is thought that telomeres structure can switch between a closed, protected state and an open, extendable state, which allows the DNA terminus to undergo replication. The protected state is necessary for safeguarding the integrity of genomic material, whereas the extendable state allows the enzyme telomerase to extend short telomeres [23]. The length of telomeric repeats varies between chromosomes and between species. In human chromosomes, the telomeric repeats length is between 0.5 and 15 kilobase (kb) pairs. In addition, the length of these repeats is dependent on the type of tissue, the age of the donor and the replicative history of the cells. For example, the average telomere length declines significantly with increasing age in human nucleated blood cells [24].

Telomerase is an enzyme that maintains telomere length. It is a ribonucleoprotein complex that is composed of RNA and protein components [25]. The major components of the active telomerase complex are telomerase reverse transcriptase (TERT), a telomerase RNA component (TERC) and dyskerin. Dyskerin is a protein that binds to TERT and TERC which increases the stability of the complex [26, 27]. Telomerase elongates the telomere sequence in mammals and yeast by binding to the open ends of the G-strand. It is highly expressed in highly proliferative cells such as stem cells, progenitor cells, lymphocytes, skin keratinocytes and cancer cells [25]. 
Telomeres are the linear chromosomes' solution in protecting their ends from breaking down and degradation and avoid recognition and processing as double-strand breaks [28]. Studies carried out in yeast and other single organisms have showed that the functions of the telomeres include protection from the chromosomal recombination, end-to-end fusion, recognition as damaged DNA, the determination of chromosomal localization within the nucleus and to regulate the cell capacity for replication [21]. It is the last function of telomeres which has received scientists' interest for studies of cellular senescence and organismal aging.

\section{TELOMERE AND REPLICATIVE AGEING}

Telomeres are lost with every cell division. This is due to the intrinsic inability of the replication machinery to copy the ends of linear molecules [29]. Based on the analysis of cultured human fibroblasts and lymphocytes, the rate of loss of telomeres is 50-100 bp per cell division [9]. As a result, the number of cell division is limited. For instance, the cultured human fibroblasts are only able to divide 50 to 80 times. The process of limiting the cell division is termed replicative aging [30]. Replicative aging is thought to form a protection from cancer. However, the limitation on cell division has led to the aging process. To understand the reason for this limitation, it is best to appreciate the disposable soma theory [31]. The disposable soma theory proposes that the rate at which the species age is the balance between the energy devoted to reproduction versus somatic repair. This means that if too much energy is invested in the repair of somatic cells, less energy is left for reproduction and vice versa. Species that are unable to survive very long due to the high mortality rate must invest most of their energy in reproduction rather than cell repair. For example, a mouse that sufficiently repaired itself for 20 years is making bad investment since most mice will be eaten by its predators within 3 months. Therefore, it is better for the mice to invest more energy in the early reproduction and less in maintenance and repair [30]. As humans have longer average survival, we have been evolutionarily selected to invest more energy on tissue maintenance and repair as compared to reproduction unlike mice. However, the variety of tissue maintenance and repair processes such as the efficiency of DNA repair, protection against oxidative damage and others limit the amount of energy invested and contribute to aging [30].

Apoptosis of damaged cells and replacing them with new ones are efficient ways of keeping cells healthy. Besides that, replacing dying cells with new healthy cells can dilute the buildup of 'unrepairable and indigestible' products that can contribute to aging. Nonetheless, using cell turnover to repair tissues may carry risk since mistakes can occur during DNA replication. These mistakes can lead to harmful mutations which will then lead to cancer [32]. Therefore, by limiting the total number of times a cell could divide provides a powerful barrier for the body from cancer formation [33].

\section{TELOMERES AND CELLULAR SENESCENCE}

It is thought that the loss of telomeres can induce antiproliferative signals which result in cellular senescence $[8,10,34]$. Cellular senescence triggered by telomere shortening is termed replicative senescence. Replicative senescence is caused by the 'uncapping' of critically shortened telomeres. This happens when telomere-binding proteins are no longer protecting telomeres, making telomeres recognized as single and lead to the breaking of the double-strand DNA. As a consequence, the cells senesce and can remain viable for years [35]. The accumulation of senescent cells is recognized as one of the two mechanisms which probably contribute to aging. The production of different constellation of proteins as compared to those that are nonsenescent but quiescent adjacent cell during the accumulation of senescent cells is believed to change the homeostasis of that tissue and lead to aging [35]. Studies reported abundant senescent cells in telomerase null mice [36]. The senescent cells are usually marked using beta galactosidase staining and these cells are always associated with changes in p53, p16 and p21 expression [37-39]. The accumulation of senescent cells may also lead to another mechanism of aging which is the loss of stem cells function [40]. Stem cells are important because they maintain the homeostasis of tissues by replenishing senescent and apoptotic cells. Besides that, they repair damage that occurs throughout life [41]. Various studies reported the loss of stem cell function through telomere shortening in a variety of tissues and experimental systems [25]. The loss of stem cell functions impair tissue repair and hence weaken the tissue functions and lead to aging [40].

\section{TELOMERES AND HUMAN PREMATURE AGING DISEASES}

Other than that, studies on several human premature aging syndromes like congenital dyskeratosis and aplastic anaemia showed that these two syndromes are linked to the mutations in telomerase or in proteins which directly affect telomerase activity. These syndromes are also characterized by a faster rate of telomere attrition with age [42]. Besides that, other human premature age syndromes like NBS1 (Nijmegan breakage syndrome), MRE11 (Ataxia telangiectasia-like disorder), WRN (Werner syndrome), BLM (Bloom syndrome), ATM (Ataxia telangiectasia) and FANC (Fanconi anemia) are characterized by an accelerated rate of telomere attrition and chromosomal stability as well [29]. However, it is important to take note that oxidative damage can 
accelerate the rate of telomere shortening [43]. By taking into account that oxidative damage contributes to aging, it is conceivable that telomere shortening reflects both proliferative history of a cell and the accumulation of oxidative damage [40].

\section{TELOMERES AND HUMAN AGING ASSOCIATED DISEASES}

Various studies have reported the association between human aging-associated diseases and telomere length [44]. An example of human aging-associated disease is cancer. The link between the telomere and cancer was first proposed when it was found that telomerase expression or reexpression and activity can be detected in more than $90 \%$ of tumor samples [45]. In addition, shorter telomere length can also lead to the cancer development. Clinical data showed that the telomere length in lymphocytes is shorter in subjects with different types of cancer which includes cancers of the head and neck, bladder, lung, prostate, breast and kidney [46].

Another example of human aging associated disease is Alzheimer's disease (AD). In AD, factors such as cell senescence, oxidative stress and aging are all important factors in its pathogenesis [47]. These important factors also directly influence telomere length $[6,48,49]$. Studies have shown that the telomere length in $\mathrm{T}$ lymphocyctes of $\mathrm{AD}$ patients is correlated with the disease status, suggesting that systemic immune system had been altered in AD pathogenesis [50]. Moreover, evidence suggests that neurons in AD may be attempting to undergo cell division [51,52] thereby invoking telomerase [53]. Another study that characterizes telomere integrity and telomerase activity in the brains of $\mathrm{AD}$ patients has shown that the neuronal telomeres were significantly shorter in hippocampal neurons of AD patients compared with that in control subjects. They also found that there is a loss of nuclear localization of TERT in the pyramidal neurons of AD patients as compared to control [53]. These findings suggest that telomere length plays a role in Alzheimer's disease.

Interestingly, recent studies established a link between telomere dysfunction with metabolic disorders. Telomere shortening-associated DNA damage response represses PGC-1 alpha and PGC-1 beta which are important regulator of mitochondrial biogenesis or function and diverse metabolic processes [54]. Therefore, suggested that telomere dysfunction may contribute to age-related disease and decline through metabolic changes [55]. Studies on RAP1 further linked to previous studies, the deletion of the telomere binding protein RAP1 leads to obesity and insulin resistance by repressing the PGC-1 alpha [56].

\section{Conclusion}

Telomeres play important roles in aging. It has been well established that telomeres are associated with aging through processes of replicative aging and cellular senescence. Besides that, it has been shown that telomere biology can manifest human premature aging diseases and human aging associated diseases. Further insights into these diseases might provide us better understanding in the roles played by the telomere biology in aging. As we understand more, we might provide a new pathway to combat these diseases.

\section{Acknowledgement}

This review was supported by the Universiti Sains Malaysia Short Term Grants (304/PPSG/61312032 and 304/PPSG/61312017).

\section{REFERENCES}

[1] K. Christensen, G. Doblhammer, R. Rau, J.W. VaupelK, Ageing populations: the challenges ahead, The Lancet. 2009; 374(9696): 1196-1208.

[2] B. Gompertz, On the nature of the function expressive of the law of human mortality, and on a new mode of determining the value of life contingencies, Philosophical transactions of the Royal Society of London. 1825; 115:513-583.

[3] G. Martin, C. Sprague, and C. Epstein, Replicative life-span of cultivated human cells. Effects of donor's age, tissue, and genotype, Laboratory investigation; a journal of technical methods and pathology: 1970. 23(1):86-92.

[4] E. Sahin and R.A. DePinho, Linking functional decline of telomeres, mitochondria and stem cells during ageing, Nature. 2010; 464(7288):520-528.

[5] L. Hayflick and P.S. Moorhead, The serial cultivation of human diploid cell strains, Experimental cell research. 1961; 25(3):585621.

[6] C.B. Harley, A.B. Futcher, and C.W. Greider. Telomeres shorten during ageing of human fibroblasts, Nature, 345(6274), 1990, 458-60.

[7] N.D. Hastie, M. Dempster, M.G. Dunlop, A.M. Thompson, D.K. Green, R.C. Allshire, Telomere reduction in human colorectal carcinoma and with ageing, Nature. 346(6287), 1990, 866-868.

[8] C.B. Harley. Telomere loss: mitotic clock or genetic time bomb?, Mutation Research/DNAging, 256(2), 1991, $271-282$.

[9] R.C. Allsopp, H. Vaziri, C. Patterson, S. Goldstein, E.V. Younglai, A.B. Futcher, C.W. Greider, C.B. Harley, Telomere length predicts replicative capacity of human fibroblasts, Proceedings of the National Academy of Sciences, 89(21), 1992, 10114-10118. Y. Zou, A. Sfeir, S.M. Gryaznov, J.W. Shay and W.E. Wright, Does a sentinel or a subset of short telomeres determine replicative senescence?, Molecular biology of the cell, 15(8), 2004, 3709-3718.

[11] H. Vaziri and S. Benchimol, From telomere loss to p53 induction and activation of a DNA-damage pathway at senescence: the telomere loss/DNA damage model of cell aging, Experimental gerontology, 31(1), 1996, 295-301.

[12] H. Takai, A. Smogorzewska, and T. de Lange. DNA damage foci at dysfunctional telomeres, Current Biology, 13(17), 2003, $1549-1556$ 
[13] L. Chin, S.E. Artandi, Q. Shen, A. Tam, S.L. Lee, G.J. Gottlieb, C.W. Greider, R.A.L. DePinho, p53 deficiency rescues the adverse effects of telomere loss and cooperates with telomere dysfunction to accelerate carcinogenesis, Cell, 97(4), 1999, 527538.

[14] K.K. Wong, R.S. Maser, R.M. Bachoo, J. Menon, D.R. Carrasco, Y. Gu, F.W. Alt, R.A. DePinho, Telomere dysfunction and Atm deficiency compromises organ homeostasis and accelerates ageing, Nature, 421(6923), 2003, 643-648.

[15] S. Ferrón, H. Mira, S. Franco, M. Cano-Jaimez, E. Bellmunt, C. Ramírez, I. Fariñas, M.A. Blasco, Telomere shortening and chromosomal instability abrogates proliferation of adult but not embryonic neural stem cells, Development, 131(16), 2004, 40594070 .

[16] I. Flores and M.A. Blasco, A p53-dependent response limits epidermal stem cell functionality and organismal size in mice with short telomeres, PLoS One, 4(3), 2009, e4934.

[17] E.H. Blackburn, Structure and function of telomeres, Nature, 350(6319), 1991, 569-573.

[18] V.A. Zakian, Telomeres: beginning to understand the end, Science, 270(5242), 1995, 1601-1607.

[19] D.E. Gomez, R.G. Armando, H.G. Farina, P.L. Menna, C.S. Cerrudo, P.D. Ghiringhelli, D.F. Alonso, Telomere structure and telomerase in health and disease (Review), International journal of oncology, 41(5), 2012, 1561-1569.

[20] S. Khan, A.A. Chuturgoon and D.P. Naidoo, Telomeres and atherosclerosis, Cardiovascular journal of Africa, 23(10), 2012, 563-571.

[21] R.J. Hodes, Telomere length, aging, and somatic cell turnover, The Journal of experimental medicine, 190(2), 1999, $153-156$.

[22] H.J. Lipps and D. Rhodes, G-quadruplex structures: in vivo evidence and function, Trends in cell biology, 19(8), 2009, 414-422.

[23] J.A. Stewart, M.F. Chaiken, F. Wang and C.M. Price, Maintaining the end: roles of telomere proteins in end-protection, telomere replication and length regulation, Mutation Research/Fundamental and Molecular Mechanisms of Mutagenesis, 730(1), 2012, 12-19.

[24] G. Aubert and P.M. Lansdorp, Telomeres and aging, Physiological reviews, 88(2), 2008, 557-579.

[25] I. Flores, R. Benetti and M.A. Blasco. Telomerase regulation and stem cell behavior, Current opinion in cell biology, 18(3), 2006, 254-260.

[26] C.W. Greider and E.H. Blackburn. Identification of a specific telomere terminal transferase activity in Tetrahymena extracts, Cell, 43(2), 1985, 405-413.

[27] S.B. Cohen, M.E. Graham, G.O. Lovrecz, N. Bache, P.J. Robinson and R.R. Reddel, Protein composition of catalytically active human telomerase from immortal cells, Science, 315(5820), 2007, 1850-1853.

[28] K. Kobryn and G. Chaconas, The circle is broken: telomere resolution in linear replicons, Current opinion in microbiology, 4(5), 2001, 558-564.

[29] M.A. Blasco, Telomeres and human disease: ageing, cancer and beyond, Nature Reviews Genetics, 6(8), 2005, 611-622

[30] W.E. Wright and J.W. Shay, Telomere biology in aging and cancer, Journal of the American Geriatrics Society, 53(9s), 2005, S292-S294.

[31] T. Kirkwood, The nature and causes of ageing, Ciba Foundation Symposium, 134,1988,193-207.

[32] B. Vogelstein and K.W. Kinzler. The multistep nature of cancer, Trends in Genetics, 9(4), 1993, 138-141.

[33] W.E. Wright and J.W. Shay, Time, telomeres and tumours: is cellular senescence more than an anticancer mechanism?, Trends in cell biology, 5(8), 1995, 293-297.

[34] J.W. Shay, Aging and cancer: are telomeres and telomerase the connection?, Molecular medicine today, 1(8), 1995, 378-384.

[35] J.W. Shay and W. Wright, Hallmarks of telomeres in ageing research, The Journal of Pathology, 211(2), $2007,114-123$.

[36] A. Satyanarayana, S.U. Wiemann, J. Buer, J. Lauber, K.E. Dittmar, T. Wüstefeld, M.A. Blasco, M.P. Manns, K.L. Rudolph, Telomere shortening impairs organ regeneration by inhibiting cell cycle re-entry of a subpopulation of cells, The EMBO journal, 22(15), 2003, 4003-4013.

[37] D.N. Shelton, E. Chang, P.S. Whittier, D. Choi, W.D. Funk. Microarray analysis of replicative senescence, Current Biology, 9(17): 1999, 939-945.

[38] H. Oeseburg, D. Iusuf, P. van der Harst, W.H. van Gilst, R.H. Henning, A.J. Roks. Bradykinin protects against oxidative stressinduced endothelial cell senescence, Hypertension, 53(2), 2009, 417-422.

[39] G.P. Dimri, X. Lee, G. Basile, M. Acosta, G. Scott, C. Roskelley, E.E. Medrano, M. Linskens, I. Rubelj, O. Pereira-Smith, et al, A biomarker that identifies senescent human cells in culture and in aging skin in vivo, Proceedings of the National Academy of Sciences, 92(20), 1995, 9363-9367.

[40] M. Collado, M.A. Blasco and M. Serrano, Cellular senescence in cancer and aging, Cell, 130(2), 2007, $223-233$.

[41] T.A. Rando, The immortal strand hypothesis: segregation and reconstruction, Cell, 129(7), 2007, $1239-1243$.

[42] P.J. Mason and M. Bessler, Heterozygous telomerase deficiency in mouse and man: when less is definitely not more, Cell Cycle, 3(9), 2004, 1125-1127.

[43] T. Zglinicki and C. Martin-Ruiz, Telomeres as biomarkers for ageing and age-related diseases, Current molecular medicine, 5(2), 2005, 197-203.

[44] R.M. Cawthon, K.R. Smith, E. O'Brien, A. Sivatchenko, R.A. Kerber, Association between telomere length in blood and mortality in people aged 60 years or older, The Lancet, 361(9355), 2003, 393-395.

[45] J.W. Shay and I.B. Roninson. Hallmarks of senescence in carcinogenesis and cancer therapy, Oncogene, 23(16), 2004, 29192933.

[46] X. Wu, C.I. Amos, Y. Zhu, H. Zhao, B.H. Grossman, J.W. Shay, S. Luo, W.K. Hong, M.R. Spitz, Telomere dysfunction: a potential cancer predisposition factor, Journal of the National Cancer Institute, 95(16), 2003, 1211-1218.

[47] M.A. Smith, L.M. Sayre, V.M. Monnier and G. Perry, Radical AGEing in Alzheimer's disease, Trends in neurosciences, 18(4), 1995, 172-176.

[48] C.J. Proctor and T.B. Kirkwood, Modelling telomere shortening and the role of oxidative stress, Mechanisms of ageing and development, 123(4), 2002, 351-363.

[49] S. Kawanishi and S. Oikawa, Mechanism of telomere shortening by oxidative stress, Annals of the New York Academy of Sciences, 1019(1), 2004, 278-284.

[50] L.A. Panossian, V.R. Porter, H.F. Valenzuela, X. Zhu, E. Reback, D. Masterman, J.L. Cummings, R.B. Effros, Telomere shortening in T cells correlates with Alzheimer's disease status, Neurobiology of aging, 24(1), 2003, 77-84.

[51] A. McShea, P.L. Harris, K.R. Webster, A.F. Wahl, M.A. Smith, Abnormal expression of the cell cycle regulators P16 and CDK4 in Alzheimer's disease, The American journal of pathology, 150(6), 1997, 1933.

[52] A.K. Raina, X. Zhu, C.A. Rottkamp, M. Monteiro, A. Takeda, M.A. Smith, A.K. Raina, Cyclin'toward dementia, Journal of neuroscience research, 61(2), 2000, 128-133. 
S. Franco, M.A. Blasco, S.L. Siedlak, P.L. Harris, P.I. Moreira, G. Perry, M.A. Smith, Telomeres and telomerase in Alzheimer's disease: Epiphenomena or a new focus for therapeutic strategy?, Alzheimer's \& Dementia, 2(3), 2006, 164-168.

[54] E. Sahin, S. Colla, M. Liesa, J. Moslehi, F.L. Mu“ ller, M. Guo, M. Cooper, D. Kotton, A.J. Fabian, C. Walkey, et. al, Telomere dysfunction induces metabolic and mitochondrial compromise, Nature 470, 2011, 359-365.

[55] M.T. Duong and E. Sahin, RAP1: Protector of Telomeres, Defender against Obesity, Cell Reports, 3(6), 2013, 1757-1758

[56] P. Martı'nez, G. Go'mez-Lo'pez, F. Garc1'a, E. Mercken, S. Mitchell, J.M. Flores, R. de Cabo, and M.A. Blasco, RAP1 protects from obesity through its extratelomeric role regulating gene expression, Cell Reports, 3(6), 2059-2074. 